\title{
Role of Radiologic Imaging in Otosclerosis
}

\author{
Paul M. Manning ${ }^{1} \cdot$ Michael R. Shroads $^{1} \cdot$ Julie Bykowski $^{1} \cdot$ Mahmood F. Mafee $^{1}$
}

Accepted: 22 November 2021 / Published online: 4 January 2022

(c) The Author(s) 2022

\begin{abstract}
Purpose of Review To review the role of imaging in otosclerosis with an emphasis on pre- and post-operative imaging evaluation.

Recent Findings Pre-operative CT imaging can help define the extent of bone involvement in otosclerosis and may help avoid surgical complications due to variant anatomy or unsuspected alternative causes of conductive hearing loss. In patients with recurrent hearing loss after surgery, CT imaging can clarify prosthesis position and re-assess anatomy.

Summary CT imaging complements otologic exam and audiometry findings in patients with suspected otosclerosis, for pre-operative planning, and post-operative assessment for patients with recurrent symptoms.
\end{abstract}

Keywords Computed tomography (CT) · Otosclerosis · Semicircular canal dehiscence · Otodystrophy $\cdot$ Stapes prosthesis · Prosthesis migration

\section{Introduction}

The role of imaging in otosclerosis has expanded over the last several decades since Valvassori first reported his findings using polytomography $[1,2]$. While otosclerosis can be diagnosed with history, otologic exam findings, and audiologic testing, and confirmed at surgery [3], access to imaging has become more widespread to complement diagnosis, presurgical planning, and evaluation of recurrent symptoms [3,4].

Non-contrast temporal bone CT is considered the gold standard for otosclerosis imaging [5,6]. With current technology, slice thickness of $0.5-0.625 \mathrm{~mm}$ is routinely achievable, allowing for thin multiplanar reformats capable of detecting abnormalities up to $1 \mathrm{~mm}$ in size [7]. Each temporal bone is independently reconstructed with a smaller field of view for imaging review. Using newer multidetector technology, the sensitivity and specificity of CT for evaluation of otosclerosis have been reported as high as $95 \%$

This article is part of the Topical Collection on Otology:

Otosclerosis and Stapes Surgery

Julie Bykowski

jbykowski@health.ucsd.edu

1 Department of Radiology, University of California San Diego, La Jolla, CA 92037, USA and $100 \%$, respectively $[3,8]$. Other modalities including magnetic resonance imaging (MRI), single-photon emission computed tomography (SPECT), and cone-beam computed tomography (CBCT) are less well established but may also play a role in otosclerosis imaging $[3,9,10]$.

\section{Imaging Findings of Otosclerosis}

To best understand the imaging features of otosclerosis, it is helpful to understand the embryologic development of the otic capsule and the histopathology of otosclerosis. The bony labyrinth is a hard and uniformly dense bone with a distinctly different texture than the surrounding parts of the petrous pyramid (except for the modiolus). The otic capsule develops from a preexisting cartilage model and is thus endochondral bone. The inner endosteal layer and the middle (thicker) endochondral layer of the otic capsule form in mid-fetal life and remain relatively inert and unchanged throughout life [11, 12]. Otosclerosis primarily involves the endochondral layer. Otosclerosis is a primary focal spongifying process which alters the ivory-hard avascular endochondral bone of the otic capsule, and irregular, highly vascular ("Schwartze sign"), foci of Haversian bone tissue develops $[11,13]$. Histologically, otospongiosis is characterized by enlargement of the perivascular spaces, osteoclastic bone resorption, and new immature bone formation [13]. In the 
later stages of the disease, the lamellar bone may be deposited [13]. In $80-90 \%$ of otospongiosis, a focus is found just in front of the oval window at the fissula (depression) ante fenestram, the most common site of involvement. The fissula ante fenestram and the fossula post fenestram develop as outpouchings from the vestibule anterior and posterior to the oval window, respectively. They are composed of a strip of altered precartilage which gradually undergoes necrosis and eventually is replaced by connective tissue centrally. As the fissula ante fenestram develops, it enlarges and approaches the anterior aspect of the stapedial area. It is common to have variations in the size, shape, and amount of cartilage around the fissula ante fenestram [14]. The fossula post fenestram develops similarly to the fissula ante fenestram and approaches the posterior aspect of the stapedial area. Cartilaginous changes are less common in the fossula post fenestram compared to the fissula ante fenestram, present in only 5\% of temporal bone specimen [15].

On CT, the normal otic capsule appears uniformly dense, unlike the surrounding petrous Haversian bone which contains marrow. The imaging findings in otosclerosis largely depend on the phase of the disease and the location of involvement (Fig. 1). Classically otosclerosis is described in two phases, an active otospongiotic phase and an inactive mature otosclerotic phase [16-20]. In the active phase, the earliest CT finding is hypodensity at the fissula ante fenestram $[16,17]$. As otosclerosis progresses, disease may extend beyond the fissula ante fenestram to the peri-cochlear region, described as retrofenestral disease. Active retrofenestral disease is predominantly characterized by hypodensity about the cochlea, and a distinctive "double ring" sign can sometimes be seen $[18,19,20]$. In the inactive otosclerotic phase, the findings can be more difficult to appreciate. The degree of sclerosis can be variable, and the only finding may be subtle contour abnormality or scalloping [16, 17, 21•]. CT has been shown to be less sensitive for the evaluation of inactive otosclerotic disease, although active and inactive disease is often found to coexist. It is important to carefully assess for bilateral involvement, as the appearance and symptoms may be asymmetric.

Several CT classification and grading systems have been proposed for evaluation of otosclerosis [6, 22, 23], largely based on active versus inactive disease and location of involvement. These classification systems have shown variable success in prediction of disease severity, prognosis, and likelihood for successful surgery, but currently, no imagingbased classification system has been universally accepted $[22,23]$. Similarly, authors have proposed different checklist approaches to reviewing and reporting imaging of otosclerosis [7]. Preliminary investigations suggest that quantitative CT attenuation measurements may serve as an additional complimentary method to detect otosclerosis [2, 24].

MRI findings in the evaluation of otosclerosis are less established. Most patients with suspected otosclerosis

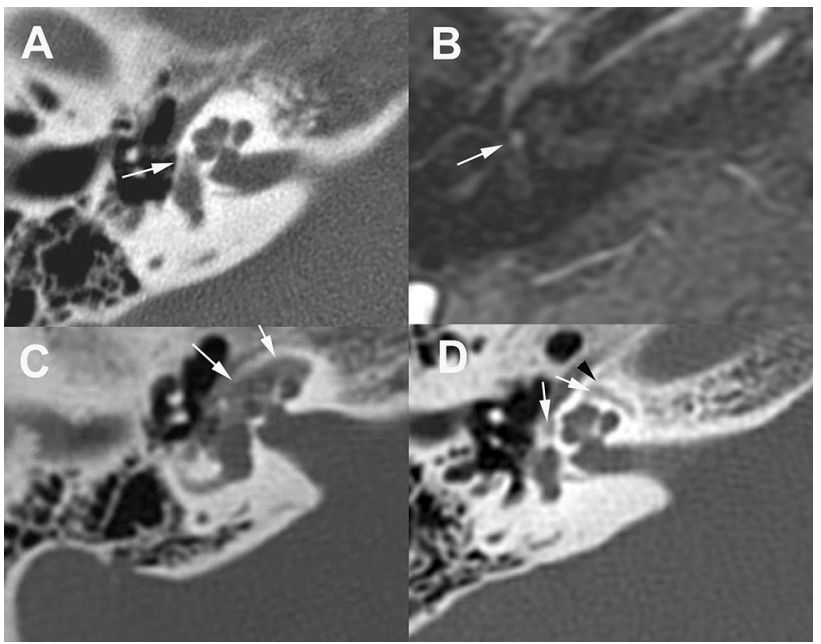

Fig. 1 Imaging findings of otosclerosis. A. Active antefenestral otosclerosis. Axial CT demonstrates focal hypodensity in the region of the fissula ante fenestram (arrow). B. Active antefenestral otosclerosis. Axial post-contrast T1 weighted MRI in the same patient as Figure A shows subtle enhancement at the fissula ante fenestram (arrow). C. Active retrofenestral otosclerosis. Axial CT demonstrates diffuse hypodensity adjacent to the cochlea (arrows). D. Combined active and inactive retrofenestral otosclerosis. Axial CT demonstrates hypodensity about the cochlea indicating active otosclerosis (white arrows) with blurring of the margin between the affected region and the adjacent otic bone (black arrowhead), findings which can indicate combined active and inactive otosclerosis.

present with conductive hearing loss are initially imaged with CT; however, for patients who present with mixed hearing loss, sensorineural hearing loss, or tinnitus, otosclerosis may not be suspected, and these patients may be first imaged by MRI. The normal otic capsule appears hypointense on all MRI sequences, unlike petrous Haversian bone. Additionally, the normal otic capsule is comprised of avascular endochondral bone which does not enhance. MRI findings of otosclerosis are subtle and easily overlooked. Classic antefenestral involvement is less commonly identified on MRI, whereas retrofenestral involvement is more conspicuous and is characterized by intermediate T1 signal and mildmoderate enhancement $[9,25,26]$. Occasionally, curvilinear increased $\mathrm{T} 2$ signal in the peri-cochlear region can also be seen [26]. This is not a finding exclusive to otosclerosis, as retrofenestral enhancement is also present in the acute/ subacute phase of labyrinthitis ossificans [27].

Currently, there is limited data for the role of SPECT and CBCT in the evaluation of otosclerosis [10, 28]. A study assessing diphosphonate SPECT for the evaluation of otosclerosis demonstrated that increased temporal bone uptake on SPECT was sensitive for otosclerosis and correlated with temporal bone $\mathrm{CT}$ findings, although the spatial resolution of SPECT was limited compared to CT [10]. CBCT is more widely used for dental evaluation but can identify bone changes of otosclerosis [29]. 


\section{Clinical and Imaging Mimics of Otosclerosis}

Many alternative causes of conductive hearing loss can be excluded based on history, otoscopy, and audiometric evaluation. However, causes of conductive hearing loss may occasionally be misdiagnosed as otosclerosis, leading to surgical complication or failed surgery. Occasionally chronic middle ear infection, tympanosclerosis, and cholesteatoma (particularly congenital cholesteatoma) in the antrum, fossa incudis, and petrous juxta labyrinth are difficult to detect by otoscopy alone. Small masses such as meningioma, schwannoma, and metastasis can mimic clinical findings of otosclerosis [30]. Imaging may be of particular benefit in cases with mixed or sensorineural hearing loss. It is also important to note if patients have a systemic disease which may have complications mimicking otosclerosis. Rare cases include symptoms related to extramedullary hematopoiesis, inflammatory processes such as chronic inflammatory demyelinating polyneuropathy (CIDP) involving the facial nerve and chorda tympani, among other case reports. The combination of CT and MRI has proved the most valuable for detection of unsuspected cholesteatoma and intratympanic masses in patients with clinically suspected stapedial cochlear otosclerosis [31, 32].

Conductive hearing loss due to ossicular discontinuity, fusion, or fracture is usually evident by direct visualization, pneumatic manipulation, or acoustic reflex testing, but occasionally, these findings may not be detectable by clinical exam alone [30]. In these cases, CT can help define ossicular chain integrity. While imaging resolution has improved, a negative CT scan does not exclude otosclerosis or mimics such as incus lentiform process necrosis/osteolysis.

$\mathrm{CT}$ is also useful to define extent of other otodystrophies which may present with conductive hearing loss including Paget's disease, osteogenesis imperfecta, fibrous dysplasia, and osteopetrosis. In Paget's disease, demineralization tends to be more severe and extensive $[33,34]$ and is visible throughout the calvarium and skull base, not restricted to the classic location for otosclerosis [35]. Additionally, pagetoid involvement tends to be asymmetric [36]. Imaging findings of osteogenesis imperfecta tend to be more severe, with bilateral involvement, and sometimes with involvement of the ossicular chain, a finding not seen in otosclerosis (although, generally, the diagnosis is known prior to imaging due to systemic features) [37]. Fibrous dysplasia typically appears as osseous expansion with a ground-glass matrix. Rarely, fibrous dysplasia can be isolated to the ossicles, resulting in pure conductive hearing loss. Osteopetrosis involvement of the temporal bone is often diffuse, symmetric, and bilateral with marked bony sclerosis that can result in narrowing of the internal auditory canal, without the prominent volume expansion seen in fibrous dysplasia [36, 38].
Other processes such as otosyphilis and post-radiation changes can cause a demineralized appearance of the otic capsule, mimicking otosclerosis on imaging. In otosyphilis, demineralization tends to be more irregular, hazy, and permeative. Additionally, otosyphilis can involve the ossicular chain, a finding which does not occur with otosclerosis [39, $40,41,42]$. Although the clinical context may allow for differentiation, in the case of post-radiation change, permeative demineralization should be visible in the central and posterior skull base in addition to any visible changes in the otic capsule [36].

\section{Pre-surgical Imaging}

Imaging can help detect known risk factors for stapes surgery and findings associated with failed stapes surgery (Fig. 2). Obliterative mature otosclerosis can be evaluated by CT, characterized by extensive thickening of the stapes footplate and filling of the oval window niche producing a "lobsterclaw" fixation of the stapes footplate [43]. Pre-operative knowledge of obliterative otosclerosis can be helpful for appropriate planning and patient counseling [43, 44•, 45, 46]. Additionally, CT can help identify whether otosclerosis involvement extends to the round window and whether there is obliteration, overgrowth, or occlusion of the round window which can result in failed stapes surgery [30, 47]. Third window defects can also result in failed stapes surgery but are readily detected by CT. Most frequently, third window defects are due to dehiscence of the superior semicircular canal [48], but careful inspection of the lateral and posterior semicircular canals, vestibule and vestibular aqueduct, and cochlea are important to avoid missing subtle defects elsewhere [49]. Labyrinthitis ossificans can also be detected by $\mathrm{CT}$, characterized by various degrees of mineralization/ossification within the periotic labyrinth and membranous labyrinth. Labyrinthitis ossificans may contribute to sensorineural and/or mixed hearing loss which would not be corrected by prosthesis placement and can also contribute to failed stapes surgery [44•].

Several anatomic variations may affect surgical approach. Variations of the ossicular chain can have surgical implications, in particular variation in the size and morphology of the lentiform process of the incus. Although evaluation of the lentiform process of the incus is near the limit of CT resolution, suspected variations can be conveyed, preparing the surgeon for potential prosthesis adjustment [30, 46]. Coronal CT profiles the tympanic facial nerve canal, for detection of canal dehiscence or nerve prolapse covering the oval window niche and cochlear promontory [50]. In situations where the overhanging facial nerve crosses the oval window, the stapes footplate can directly attach to the facial nerve, placing the patient at risk for facial nerve 

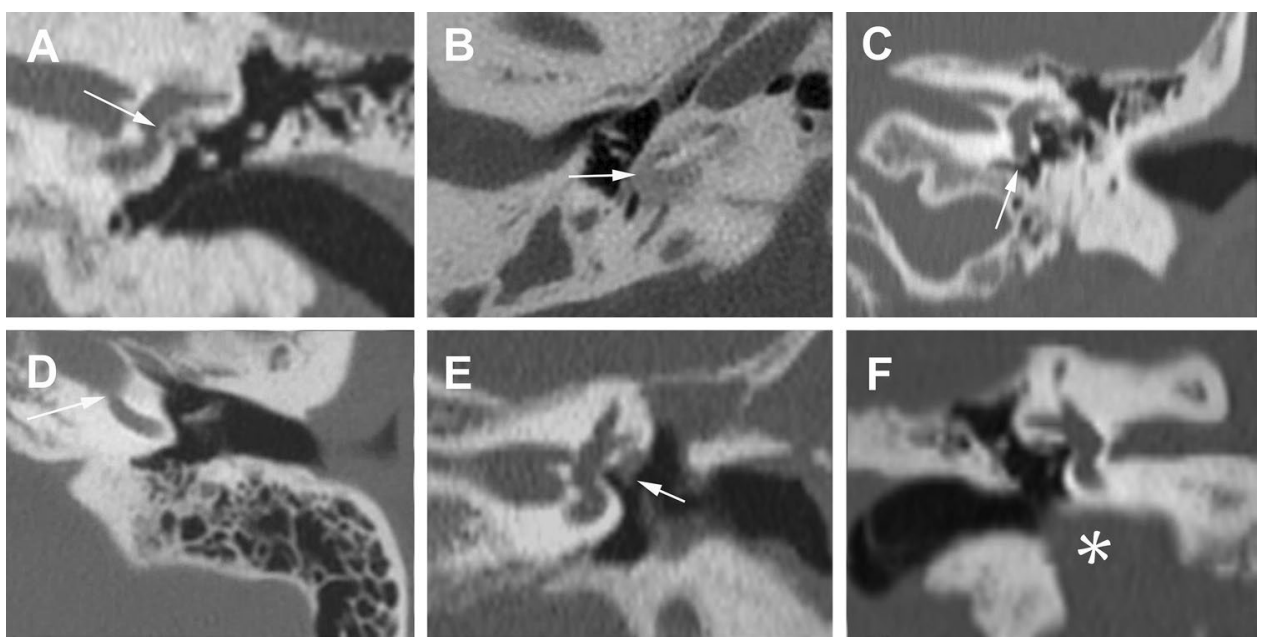

Fig. 2 Risk factors for surgery and findings associated with failed surgery. A. Obliterative otosclerosis. Coronal CT shows the osseous thickening and bone overgrowth at the stapes footplate (arrow). B. Obliterative otosclerosis. Axial CT shows bone overgrowth at the round window, associated with advanced otosclerosis. C. Round window obstruction. Coronal CT demonstrates more subtle findings of boneformation obstructing the round window (arrow) due to otoscle-

injury if a surgical repair for otosclerosis is planned [30, 50]. Pre-operative $\mathrm{CT}$ can define if there is a high riding jugular bulb, dehiscent jugular bulb, or jugular diverticulum, and if there is vascular encroachment upon the round window niche [47]. Non-contrast $\mathrm{CT}$ is sufficient to exclude aberrant internal carotid artery, to avoid surgical complication [51, 52]. Associated with the aberrant internal carotid artery, a persistent stapedial artery may appear as a soft tissue mass adjacent to the tympanic segment of the facial nerve [53]. This may cause conductive hearing loss by limiting stapes movement [54] and rarely may occur concurrently with otosclerosis [55]. A careful review of the inner ear structures is critical to identify any dysplasia that may indicate a risk for perilymph gusher at the time of stapedectomy [56]. Finally, a rare but important anatomic variant is a persistent periotic tympanomeningo fissure (Hyrtl's fissure), which can cause conductive hearing loss and is a potential route for perilymphatic congenital fistula and CSF otorrhea [57, 58]. On $\mathrm{CT}$, the tympanomeningo fissure can be seen inferior to the cochlear aqueduct.

Patients with far advanced otosclerosis [59] who develop sensorineural hearing loss (thought to be due to hyalinization of the spiral ligament [60]) or the result of ototoxic and metabolic factors [61]), may benefit from cochlear implantation [62]. Several pre-surgical imaging findings can be beneficial prior to cochlear implantation. As with stapes surgery planning, CT can allow for evaluation of labyrinthitis ossificans which can complicate cochlear implantation. Through CT, the degree of mineralization/ossification can be directly assessed [63]. CT can also evaluate for diffuse retrofenestral rosis. D. $3^{\text {rd }}$ window defect. Axial CT demonstrates focal dehiscence of the basal turn of the cochlea with the carotid canal (arrow).E. Facial nerve canal dehiscence. Coronal CT confirms an overhanging facial nerve (arrow) due to uncovered bone. F. Dehiscent jugular bulb. Coronal CT demonstrates a dehiscent jugular bulb (asterisk) extending into the tympanic cavity

disease which has been associated with an increased likelihood of facial nerve stimulation with cochlear nerve implantation, presumably due to bone thinning (spongiotic bone) proximal to the genu/labyrinthine segment leading to decreased impedance between the facial nerve and the electrode within the cochlea [22]. Few reports have described "cavitary otosclerosis" as a potential surgical pitfall for cochlear implantation $[64,65]$ as the electrode may penetrate into peri-cochlear cavities. Pre-operative knowledge of "cavitary otosclerosis" may help avoid this potential complication.

\section{Post-surgical Imaging}

The most common cause of persistent or recurrent conductive hearing loss after surgery is prosthesis migration or dislocation (Fig. 3). A well described mechanism is the "lateralized piston syndrome" where the piston migrates laterally out of the oval window, at times so far laterally that it contacts the tympanic membrane. This can lead to a distinctive delayed conductive hearing loss which temporarily improves with changes in middle ear pressure [66]. Occasionally, the piston can instead migrate medially into the vestibule. In addition to migration at the oval window, the prosthesis can dislocate at the incus, appearing on CT as a gap between the incus and the prosthesis.

Another cause of failed surgery is too short or too long of a piston; too short may not reach the oval window and too long may insert too deep into the vestibule and may contact either the saccule or utricle and lead to vertigo [67]. It is possible 


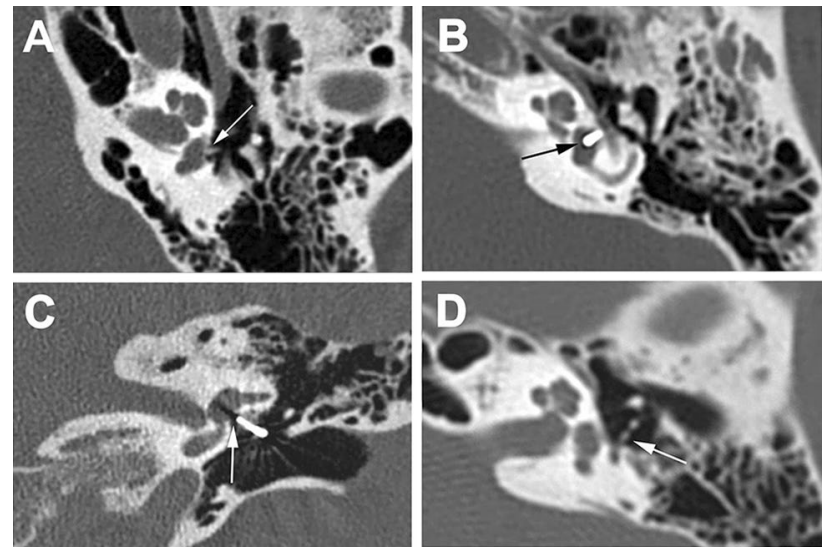

Fig. 3 Post-surgical evaluation. A. Normal prosthesis placement. Axial CT demonstrates a normally positioned prosthesis tip at the oval window (arrow). B. Medial migration of the piston. Axial CT demonstrates a medially displaced piston, terminating within the vestibule (arrow). C. Insufficient prosthesis length. Axial CT demonstrates the piston terminating lateral to the oval window (arrow). Note streak artifact associated with the metal prosthesis which can complicate evaluation. D. Dislocated prosthesis. Axial CT demonstrates posterior displacement of a non-metallic prosthesis (arrow)

to assess the length of the piston on imaging, but accurate imaging assessment is difficult and depends on the type of prosthesis used. Size is typically underestimated for fluoroplastic implants and overestimated for metallic implants due to metallic artifact [67]; therefore, imaging findings must be correlated with symptoms.

Ossicular necrosis or erosion is another cause of surgical failure which appears as erosive changes on CT imaging. Most commonly, this occurs at the incus at the prosthesis attachment, attributed to ischemia or altered stress resulting in resorption $[68,69]$. Granulation or fibrous adhesions contributing to prosthesis failure may appear as soft tissue attenuation on CT or intermediate T1 signal on MRI; however, these findings may not always be visible by imaging and may be more readily apparent during surgical exploration [42, 70]. Peri-lymphatic fistula is a rare cause of surgical failure, presenting as gas within the membranous labyrinth on imaging [44•]. Finally, progression of otosclerosis itself may result in recurrent hearing loss after surgery. CT can clarify if this is due to obliteration of the round window or progression to cochlear otosclerosis, which may result in mixed or sensorineural hearing loss $(44 \bullet, 71)$.

\section{Conclusion}

Otosclerosis is a common and important cause of hearing loss. Although uncomplicated cases of stapedial otosclerosis can be diagnosed clinically, imaging can play an important role to clarify the diagnosis, reduce operative morbidity, and assess recurrent symptoms.

\section{Compliance with Ethical Standards}

Paul M. Manning, Michael R. Shroads, Julie Bykowski, and Mahmood F. Mafee declare that they have no conflict of interest.

Human and Animal Rights and Informed Consent This article does not contain any studies with human or animal subjects performed by any of the authors.

Open Access This article is licensed under a Creative Commons Attribution 4.0 International License, which permits use, sharing, adaptation, distribution and reproduction in any medium or format, as long as you give appropriate credit to the original author(s) and the source, provide a link to the Creative Commons licence, and indicate if changes were made. The images or other third party material in this article are included in the article's Creative Commons licence, unless indicated otherwise in a credit line to the material. If material is not included in the article's Creative Commons licence and your intended use is not permitted by statutory regulation or exceeds the permitted use, you will need to obtain permission directly from the copyright holder. To view a copy of this licence, visit http://creativecommons.org/licenses/by/4.0/.

\section{References}

Papers of particular interest, published recently, have been highlighted as:

- Of importance

1. Valvassori GE. Radiologic diagnosis of cochlear otosclerosis. Laryngoscope. 1965;75(10):1563-71.

2. Valvassori GE. Imaging of the temporal bone in: Imaging of the head and neck (2nd ed). 2nd ed. Mafee MF, Valvassori GE, Becker CR, editors. Stuttgart, New York: Thieme; 2005.

3. Virk JS, Singh A, Lingam RK. The role of imaging in the diagnosis and management of otosclerosis. Otology \& neurotology : official publication of the American Otological Society, American Neurotology Society [and] European Academy of Otology and Neurotology. 2013;34(7):e55-60.

4. Wegner I, van Waes AMA, Bittermann AJ, Buitinck SH, Dekker $\mathrm{CF}$, Kurk SA, et al. A systematic review of the diagnostic value of CT imaging in diagnosing otosclerosis. Otol Neurotol. 2016;37(1).

5. Lee TL, Wang MC, Lirng JF, Liao WH, Yu EC, Shiao AS. Highresolution computed tomography in the diagnosis of otosclerosis in Taiwan. Journal of the Chinese Medical Association : JCMA. 2009; 72(10):527-32.

6. Lee TC, Aviv RI, Chen JM, Nedzelski JM, Fox AJ, Symons SP. CT grading of otosclerosis. AJNR Am J Neuroradiol. 2009;30(7):1435-9.

7. Purohit B, Hermans R, Op de Beeck K. Imaging in otosclerosis: a pictorial review. Insights Imaging. 2014;5(2):245-52.

8. Lagleyre S, Sorrentino T, Calmels M-N, Shin Y-J, Escudé B, Deguine O, et al. Reliability of high-resolution CT scan in diagnosis of otosclerosis. Otol Neurotol. 2009;30(8).

9. Goh JP, Chan LL, Tan TY. MRI of cochlear otosclerosis. Br J Radiol. 2002;75(894):502-5.

10. Berrettini S, Ravecca F, Volterrani D, Neri E, Forli F. Imaging evaluation in otosclerosis: single photon emission computed tomography and computed tomography. Ann Otol Rhinol Laryngol. 2010;119(4):215-24.

11. ME Glasscock III SGE 1990 Surgery of the ear 4 Saunders Philadelphia. 
12. Anson BJDJA. Surgical anatomy of the temporal bone. 3rd ed. Philadelphia: Saunders; 1981.

13. Nager GT. Histopathology of Otosclerosis. Arch Otolaryngol. 1969;89(2):341-63.

14. BAST TH. Development of the otic capsule: II. The origin, development and significance of the fissula ante fenestram and its relation to otosclerotic foci. Arch Otolaryngol. 1933;18(1):1-20.

15. BAST TH. Development of the otic capsule: IV. The fossula post fenestram. Arch Otolaryngol. 1938;27(4):402-12.

16. Mafee MF, Henrikson GC, Deitch RL, Norouzi P, Kumar A, Kriz R, et al. Use of CT in stapedial otosclerosis. Radiology. 1985;156(3):709-14.

17. Mafee MF, Valvassori GE, Deitch RL, Norouzi P, Henrikson GC, Capek V, et al. Use of CT in the evaluation of cochlear otosclerosis. Radiology. 1985;156(3):703-8.

18. Mafee MF, M. B, Sepahdari A, Valvassori GE. Imaging of the head and neck (3rd ed). Stuttgart, New York: Thieme; In Press.

19. Mafee MF, Valvassori GE. Imaging of temporal bone in: Ballenger's Otorhinolaryngology: head and neck surgery (17th ed). In: Snow JB, Wackym R.A., editor. Head and neck surgery. 17th ed. Shelton, CT: BC Decker Inc. 2009.

20. Mafee MF, Valvassori GE, Sepahdari AR. Imaging of temporal bone in: Ballinger's otorhinolaryngology: head and neck surgery (18th ed). Shelton, CT: BC Decker People's Medical Publishing House; 2016.

21. Sanghan N, Chansakul T, Kozin ED, Juliano AF, Curtin HD, Reinshagen KL. Retrospective Review of otic capsule contour and thickness in patients with otosclerosis and individuals with normal hearing on CT. Am J Neuroradiol. 2018;39(12):23505. This study shows that a bulging or convex contour change of the bone at the oval window/cochleariform process is indicative of otosclerosis remineralization phase, when CT bone attenuation changes of otospongiosis are no longer visually distinct.

22. Marshall AH, Fanning N, Symons S, Shipp D, Chen JM, Nedzelski JM. Cochlear implantation in cochlear otosclerosis. Laryngoscope. 2005;115(10):1728-33.

23. Rotteveel LJ, Proops DW, Ramsden RT, Saeed SR, van Olphen AF, Mylanus EA. Cochlear implantation in 53 patients with otosclerosis: demographics, computed tomographic scanning, surgery, and complications. Otology \& neurotology: official publication of the American Otological Society, American Neurotology Society [and] European Academy of Otology and Neurotology. 2004;25(6):943-52.

24. Kawase S, Naganawa S, Sone M, Ikeda M, Ishigaki T. Relationship between CT densitometry with a slice thickness of $0.5 \mathrm{~mm}$ and audiometry in otosclerosis. Eur Radiol. 2006;16(6):1367-73.

25. Youssef O, Rosen A, Chandrasekhar S, Lee HJ. Cochlear otosclerosis: the current understanding. Ann Otol Rhinol Laryngol. 1998;107(12):1076-9.

26. Purohit B, Op de Beeck K, Hermans R. Role of MRI as firstline modality in the detection of previously undiagnosed otosclerosis: a single tertiary institute experience. Insights Imaging. 2020;11(1):71.

27. Taxak P, Ram C. Labyrinthitis and labyrinthitis ossificans - a case report and review of the literature. J Radiol Case Rep. 2020;14(5):1-6.

28. Liktor B, Révész P, Csomor P, Gerlinger I, Sziklai I, Karosi T. Diagnostic value of cone-beam CT in histologically confirmed otosclerosis. European archives of oto-rhino-laryngology : official journal of the European Federation of Oto-Rhino-Laryngological Societies (EUFOS) : affiliated with the German Society for OtoRhino-Laryngology - Head and Neck Surgery. 2014;271(8):2131-8.

29. Miracle AC, Mukherji SK. Conebeam CT of the head and neck, part 2: clinical applications. Am J Neuroradiol. 2009;30(7):1285-92.
30. Curtin HD. Imaging of conductive hearing loss with a normal tympanic membrane. Am J Roentgenol. 2015;206(1):49-56.

31. Mafee M, Nozawa A. Primary and secondary cholesteatomas, cholesterol granuloma and mucocele of the temporal bone: role of CT and MRI with emphasis on diffusion-weighted imaging. Operative Techniques in Otolaryngology-Head and Neck Surgery. 2013.

32. Tuan A, Chen J, Mafee M. Glomus tympanica and other intratympanic masses: role of imaging. Operative techniques in otolaryngology-head and neck surgery. 2013;25.

33. Hamed AAW, Fayad JN. Presence of otosclerosis and paget lesions in the same temporal bone. Otology \& neurotology : official publication of the American Otological Society, American Neurotology Society [and] European Academy of Otology and Neurotology. 2009;30(8):1232-3.

34. Shonka DC Jr, Kesser BW. Paget's disease of the temporal bone. Otol Neurotol. 2006;27(8).

35. Tan JH, Miyakoshi A, Mafee MF. Imaging of fibro-osseous lesions of the temporal bone. Oper Tech Otolaryngol Head Neck Surg. 2014;25(1):96-109.

36. Swartz JD. The otodystrophies: diagnosis and differential diagnosis. Semin Ultrasound CT MR. 2004;25(4):305-18.

37. Alkadhi H, Rissmann D, Kollias SS. Osteogenesis imperfecta of the temporal bone: CT and MR Imaging in Van der Hoeve-de Kleyn Syndrome. Am J Neuroradiol. 2004;25(6):1106-9.

38. d'Archambeau O, Parizel PM, Koekelkoren E, Van de Heyning P, De Schepper AM. CT diagnosis and differential diagnosis of otodystrophic lesions of the temporal bone. Eur J Radiol. 1990;11(1):22-30.

39. Sonne JE, Zeifer B, Linstrom C. Manifestations of Otosyphilis as Visualized with Computed Tomography. Otol Neurotol. 2002;23(5).

40. Ogungbemi A, Dudau C, Morley S, Beale T. Computed tomography features of luetic osteitis (otosyphilis) of the temporal bone. J Laryngol Otol. 2014;128(2):185-8.

41. Darmstadt GL, Harris JP. Luetic hearing loss: Clinical presentation, diagnosis, and treatment. Am J Otolaryngol. 1989;10(6):410-21.

42. Nadol JB. Hearing loss of acquired syphilis: Diagnosis confirmed by incudectomy. Laryngoscope. 1975;85:1888-97.

43. Ayache D, Sleiman J, Plouin-Gaudon I, Klap P, Elbaz P. Obliterative otosclerosis. J Laryngol Otol. 1999;113(6):512-4.

44. Whetstone J, Nguyen A, Nguyen-Huynh A, Hamilton BE. Surgical and clinical confirmation of temporal bone CT findings in patients with otosclerosis with failed stapes surgery. Am J Neuroradiol. 2014;35(6):1195. Authors present cases with CT images of stapedectomy failure due to incus erosion, prosthesis disconnection, dislocation from the oval window, piston re-sizing, granulation tissue, obliterative otosclerosis, and labyrinthine ossificans and emphasize need to recognize semicircular canal dehiscence as a contraindication to stapes surgery, distinct from stapedectomy complications.

45. Williams MT, Ayache D, Elmaleh M, Héran F, Elbaz P, Piekarski J-D. Helical CT findings in patients who have undergone stapes surgery for otosclerosis. Am J Roentgenol. 2000;174(2):387-92.

46. Daniels RL, Krieger LW, Lippy WH. The other ear: findings and results in 1,800 bilateral stapedectomies. Otology \& neurotology : official publication of the American Otological Society, American Neurotology Society [and] European Academy of Otology and Neurotology. 2001;22(5):603-7.

47. Benson JC, Diehn F, Passe T, Guerin J, Silvera VM, Carlson ML, et al. The forgotten second window: a pictorial review of round window pathologies. Am J Neuroradiol. 2019.

48. Picavet V, Govaere E, Forton G. Superior semicircular canal dehiscence: prevalence in a population with clinical suspected otosclerosis-type hearing loss. B-ENT. 2009;5(2):83-8. 
49. Neyt P, Govaere F, Forton GEJ. Simultaneous true stapes fixation and bilateral bony dehiscence between the internal carotid artery and the apex of the cochlea: the ultimate pitfall. Otol Neurotol. 2011;32(6).

50. Wu C-M, Ng S-H, Liu T-C. Facial Nerve overlying stapes footplate as a cause of conductive hearing loss. Otol Neurotol. 2008;29(8).

51. Ibarra RA, Kesava P, Fewins JL. Congenital otosclerosis in a child with bilateral aberrant internal carotid arteries. Am J Roentgenol. 2001;176(1):263-4.

52. Sauvaget E, Paris J, Kici S, Kania R, Guichard JP, Chapot R, et al. Aberrant internal carotid artery in the temporal bone: imaging findings and management. Arch Otolaryngol-Head Neck Surg. 2006;132(1):86-91.

53. Silbergleit R, Quint DJ, Mehta BA, Patel SC, Metes JJ, Noujaim SE. The persistent stapedial artery. Am J Neuroradiol. 2000;21(3):572-7.

54. Goderie TPM, Alkhateeb WHF, Smit CF, Hensen EF. Surgical management of a persistent stapedial artery: a review. Otology $\&$ neurotology : official publication of the American Otological Society, American Neurotology Society [and] European Academy of Otology and Neurotology. 2017;38(6):788-91.

55. Breheret R, Bizon A, Tanguy JY, Laccourreye L. Persistent stapedial artery with otosclerosis. Annales d'oto-laryngologie et de chirurgie cervico faciale : bulletin de la Societe d'oto-laryngologie des hopitaux de Paris. 2009;126(5-6):259-63.

56. De Stefano A, Dispenza F, Aggarwal N, Russo A. Otosclerosis associated with type B-1 inner ear malformation. Acta Otorhinolaryngol Ital. 2010;30(3):153-5.

57. Jégoux F, Malard O, Gayet-Delacroix M, Bordure P, Legent F, Beauvillain de Montreuil C. Hyrtl's fissure: a case of spontaneous cerebrospinal fluid otorrhea. Am J Neuroradiol. 2005;26(4):963-6.

58. Mafee MF, Bradley WG, Almutairi A, Zawaideh M, Patel K. Arachnoid granulations and spontaneous cerebrospinal fluid otorrhea: role of imaging. Oper Tech Otolaryngol Head Neck Surg. 2014;25(1):74-86.

59. House HP, Sheehy JL. Stapes surgery: selection of the patient. Ann Otol Rhinol Laryngol. 1961;70:1062-8.

60. Parahy C, Linthicum FH Jr. Otosclerosis: relationship of spiral ligament hyalinization to sensorineural hearing loss. Laryngoscope. 1983;93(6):717-20.
61. Rüedi L, Spoendlin H. XL Pathogenesis of sensorineural deafness in otosclerosis. Ann Otol Rhinol Laryngol. 1966;75(2):525-52.

62. Psillas G, Kyriafinis G, Constantinidis J, Vital V. Far-advanced otosclerosis and cochlear implantation. B-ENT. 2007;3:67-71.

63. Buch K, Baylosis B, Fujita A, Qureshi MM, Takumi K, Weber PC, et al. Etiology-specific mineralization patterns in patients with labyrinthitis ossificans. Am J Neuroradiol. 2019;40(3):551-7.

64. Bou-Assaly W, Mukherji S, Srinivasan A. Bilateral cavitary otosclerosis: a rare presentation of otosclerosis and cause of hearing loss. Clin Imaging. 2013;37(6):1116-8.

65. Makarem AO, Hoang T-A, Lo WWM, Linthicum FH, Jr., Fayad JN. Cavitating otosclerosis: clinical, radiologic, and histopathologic correlations. Otology \& neurotology: official publication of the American Otological Society, American Neurotology Society [and] European Academy of Otology and Neurotology. 2010;31(3):381-4.

66. Lagleyre S, Calmels M-N, Escudé B, Deguine O, Fraysse B. Revision stapes surgery: the "lateralized piston syndrome". Otol Neurotol. 2009;30(8).

67. Warren FM, Riggs S, Wiggins RH, III. Computed tomographic imaging of stapes implants. Otol Neurotol. 2008;29(5).

68. Choudhury N, Kumar G, Krishnan M, Gatland DJ. Atypical incus necrosis: a case report and literature review. J Laryngol Otol. 2008;122(10):1124-6.

69. Fisch U, Acar GO, Huber AM. Malleostapedotomy in revision surgery for otosclerosis. Otology \& neurotology : official publication of the American Otological Society, American Neurotology Society [and] European Academy of Otology and Neurotology. 2001;22(6):776-85.

70. Rangheard A-S, Marsot-Dupuch K, Mark AS, Meyer B, Tubiana J-M. Postoperative complications in otospongiosis: usefulness of MR imaging. Am J Neuroradiol. 2001;22(6):1171.

71. Yetiser S. Revision surgery for otosclerosis: an overview. World J Otorhinolaryngol. 2015;5:21.

Publisher's Note Springer Nature remains neutral with regard to jurisdictional claims in published maps and institutional affiliations. 